\title{
LEIOMIOSSARCOMA DE CÓLON
}

\section{COLON LEIOMYOSARCOMA}

Luiz Claudio Landolfi Pereira ${ }^{1}$; Caio Henrique Carrichio Barrili1; Lucas Abdo Pereira ${ }^{2}$; Beatriz Merotti Arjona $^{2}$; Thais Abdo Pereira ${ }^{3}$.

\section{RESUMO}

Leiomiossarcomas primários do trato gastrointestinal são tumores extremamente raros e muito agressivos, apenas poucos trabalhos relatando a doença desde o estabelecimento do conceito dos tumores estromais do sistema digestório foram relatados. Reportamos um caso de leiomiossarcoma primário de cólon transverso e revisão de literatura.

Descritores: Leiomiossarcoma. Células Estromais. Neoplasias do Colo.

\section{ABSTRACT}

Primary leiomyosarcomas of the gastrointestinal (GI) tract are extremely rare and highly aggressive neoplasms, and only a small number of true cases have been reported since the concept of GI stromal tumors was established. Here, we report a case of a primary leiomyosarcoma of the transverse colon and the review of literature.

Keywords: Leiomyosarcoma. Stromal Cells. Colonic Neoplasms.

\section{INTRODUÇÃO}

Os Leiomiossarcomas são tumores malignos formados por células do músculo liso, podendo ocorrer em qualquer parte do sistema digestório, embora sejam extremamente $\operatorname{raros}^{1,2}$. Quanto a prevalência, são mais frequentes no estômago (47\%), intestino delgado (35\%), reto (12\%), cólon e esôfago $(2 \%)^{1-3}$. Apresentamos caso raro de leiomiossarcoma de cólon transverso e revisão de literatura.

\section{RELATO DO CASO}

Paciente BRB, masculino, 71 anos, internado pela equipe de endoscopia com quadro de alteração de hábito intestinal há 2 meses, obstipação intestinal, perda ponderal e anemia. Iniciou preparo para exame de colonoscopia solicitado pelo cardiologista e durante uso de manitol apresentou distensão abdominal, sem evacuação, vômitos, dor abdominal e importante rigidez abdominal. Solicitada avaliação de equipe cirúrgica. Paciente se apresentava clinicamente estável, sem hipotensão, sem taquicardia mas com importante distensão abdominal e hipertimpanismo difuso porém com flacidez abdominal. Realizado exame radiológico que mostrou importante distensão colônica e obstrução em alça fechada.

Optado por laparotomia exploradora. No ato cirúrgico observada lesão estenosante em ângulo esplênico com importante distensão colônica proximal, sem sofrimento de cólon direito, sem lesões secundárias abdominais, sem gânglios visiveis.

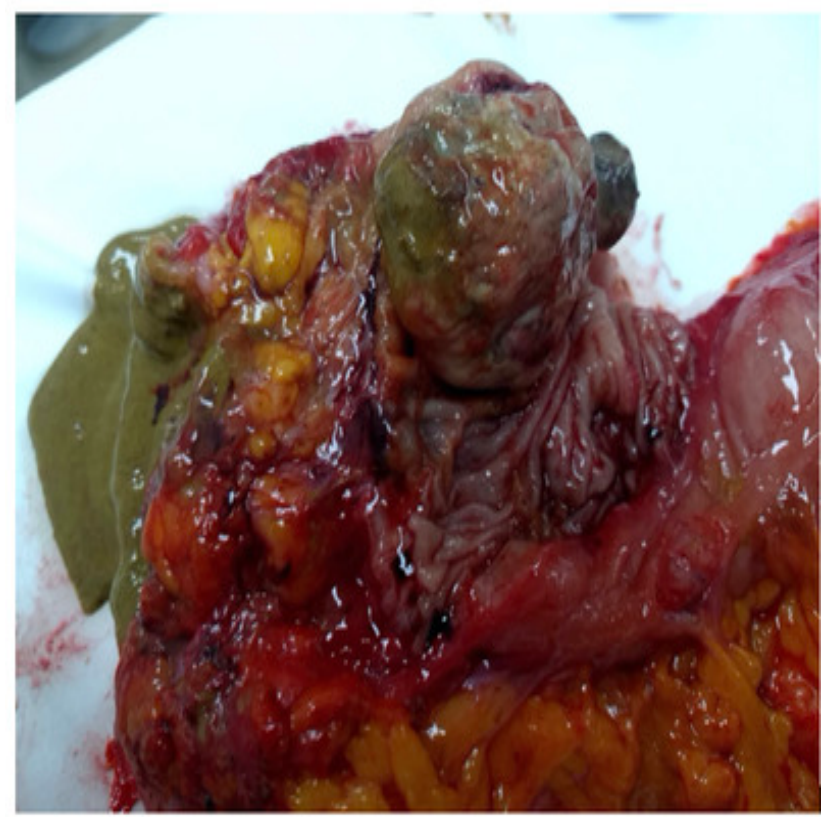

Figura 1. Lesão vegetante estenosante em ângulo esplênico, com ulcerações em mucosa comprometendo luz colônica.

\footnotetext{
${ }^{1}$ Hospital 9 de Julho - Serviço de Cirurgia do Aparelho Digestivo - São Paulo, SP, Brasil.

2 Faculdade de Medicina do ABC - Santo André, SP, Brasil.

3 Universidade de Santo Amaro - Faculdade de Medicina - São Paulo, SP, Brasil.
} 
Optado por hemicolectomia esquerda ampliada, linfadenectomia sem anastomose primária em decorrência da presença de grande quantidade de resíduos fecais e importante distensão proximal colônica. Realizada colostomia a Hartmann. Paciente evoluiu sem complicações pós-operatória, recebendo alta no $6^{\circ}$ dia $\mathrm{PO}$. Resultado da peça cirúrgica revelou neoplasia estenosante extramucosa colônica de aproximadamente $7 \mathrm{~cm}$, sugestiva de leiomiossarcoma pela imuno-histoquímica com marcadores CD 117, proteína S-100 negativas, e positivos para actina e desmina de músculo liso. Ausência de lesão detectada em linfonodos da peça cirúrgica (29 linfonodos ressecados). Exames de imagem no pós cirúrgico não detectou lesão secundária em exames de tomografias de tórax, abdome e pelve.

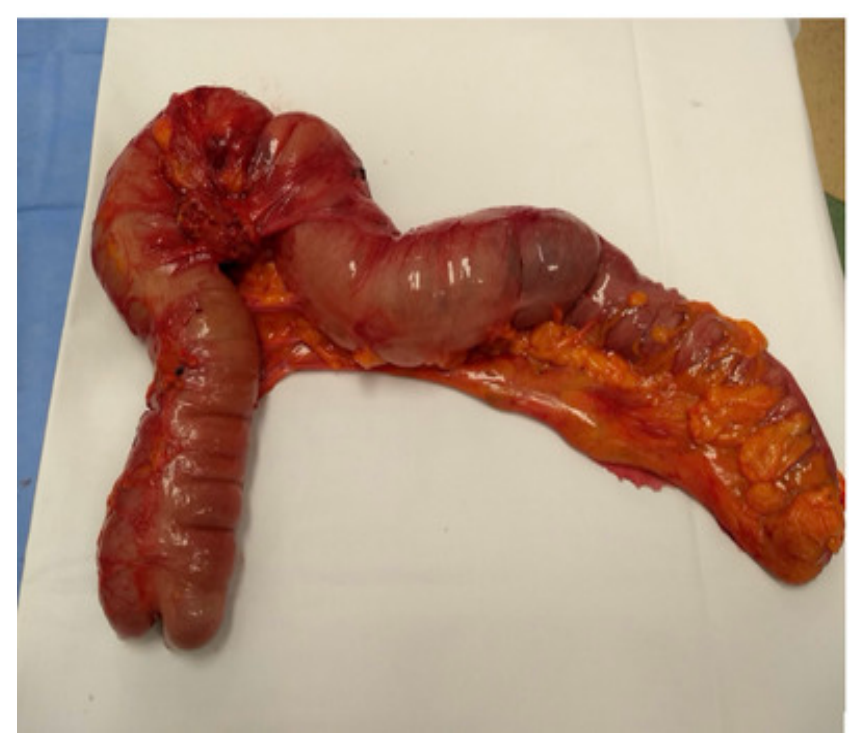

Figura 2. Hemicolectomia esquerda, lesão estenosante de ângulo esplênico de colon transverso.

\section{DISCUSSÃO}

Os leiomiossarcomas são tumores mesenquimais originados das fibras musculares da musculatura própria da parede do trato digestivo ou da muscular da muco$\mathrm{sa}^{4,5}$. Eles representam apenas $1 \%$ dos tumores do sistema digestório ${ }^{5}$. A localização colônica da doença é ainda mais rara, representando $0,1 \%$ dos tumores malignos do intestino grosso ${ }^{3}$.

No cólon encontramos os leiomiossarcomas mais frequentemente no cólon sigmoide, seguido por cólon transverso e cólon direito ${ }^{3,6}$. Não apresentam predileção por sexo $^{5}$, e acometem pacientes a partir da quinta década de vida ${ }^{4,5}$.
O quadro clínico é geralmente inespecífico, e composto por dores abdominais, anemia, alterações de hábito intestinal, massas palpáveis, hemorragia digestiva e, em casos mais avançados, sintomas de obstrução intestinal, volvo, perfuração e intussuscepção $2,4,5$.

O diagnóstico da patologia se baseia na história clínica, auxiliado por exames de imagem e endoscópicos mas, a confirmação etiológica é feita pelo exame patológico com imuno-histoquímica ${ }^{2,3,6,7}$.

A ultrassonografia de abdome total, tomografia abdominal com duplo contraste são exames amplamente utilizados na prática médica para detecção de quadros abdominais e habitualmente confirmam lesões hipodensas e hipoatenuantes em topografia colônica 2,3 . São importantes para definir a extensão da lesão e presença de lesões metastáticas. As metástases a distância dos leiomiossarcomas são mais frequentes no figado, peritônio, pulmão e $\operatorname{ossos}^{3}$. A colonoscopia é o exame de escolha para investigação de lesões colônicas, habitualmente se apresentando com lesões extramucosas expansivas, estenosantes em sua maioria, sendo difícil a diferenciação com carcinomas.

O exame definitivo para diagnóstico dos leiomiossarcomas é o anatomopatológico com imuno-histoquímica, fundamental para diferenciação dos tumores mesenquimais do trato digestivo ${ }^{3-5,8}$. A característica imuno-histoquímica dos leiomiossarcomas é a presença de marcadores positivos para actina e desmina de músculo liso, e negativos para CD 37, CD 117, proteína S-100, presentes em outras lesões mesenquimais como GISTs e Schwanomas ${ }^{3,4}$.

O tratamento é sempre cirúrgico com ressecção oncológica das lesões. A disseminação preferencial da doença se faz por via hematogênica e raramente linfática ${ }^{3}$, sendo frequente lesões secundárias durante o ato cirúrgico ${ }^{3-5}$.

O prognóstico da doença se baseia na idade dos pacientes, grau de diferenciação tumoral, tamanho das lesões, presença de doença metastática ${ }^{4,5}$. A expectativa de vida em 5 anos nos pacientes com lesões menores de $5 \mathrm{~cm}$, sem metástases e lesões de baixo grau é de aproximadamente $50 \%{ }^{4}$.

Tratamento complementar com quimioterapia, esquemas de fosfamida, doxorrubicina, doxetacel, antraciclina não se mostraram efetivos em aumentar a taxa de 
sobrevida em 5 anos ${ }^{3}$, não existindo protocolos específicos para seu tratamento em decorrência da raridade da patologia.

\section{REFERÊNCIAS}

1. Lopes A, Vieira RHC, Oyafuso MS, Rossi BM, Nagakawa WT. Leiomiossarcoma de cólon direito. Relato de caso e revisão de literatura. Rev Bras Cir 1996;86:9-11.

2. Lopes SG, Marchiori E, Brick JF, Curty Neto E, Scherman A, Silva ACG, et al. Leiomiossarcoma do intestino grosso. Relato de caso. Radiol Bras. 2001;34(2):109-12.

3. Crystal JS, Korderas K, Schwartzberg D, Tizio SC, Zheng M, Parker G. Primary Leiomyosarcoma of the colon. A report of two cases and review of the literature. Case Rep Surg. 2018;2018:6824643.

4. Kono M, Tsuji N, Ozaki N, Matsumoto N, Takaba T, Okumura N, et al. Primary leiomyosarcoma of the colon. Clin J Gastroenterol. 2015;8 (4):217-22.
5. Kouthoumpakis E, Assi H, McCarthur L, Mehdi S. High-Grade leiomyosarcoma of transverse colon presenting with bowel perforation. J Comm Support Oncol. 2016;14 (8):359-62.

6. Dendale P, Devis G, Goossens A. Leiomyosarcoma of the small intestine presenting as fever of unknown origin. Gut. 1992;33(3):411-3.

7. Silva RA, Silva MCGB, Farret Jr LC, Bergamo AC, Wawrzeniak AC. Leiomiossarcoma de jejuno: revisão de literatura. JBM. 1996;71(3):117-20.

8. Kiran P, Shiny PM, Dhanya KS, Aravindan KP. Diagnosis of leiomyosarcoma of colon. $J$ Cancer Res Ther. 2015;11(4):1035.

Recebido em: 19/05/2020

Aceito para publicação: 21/05/2020

Conflito de interesses: Não

\section{Endereço para correspondência:}

Luiz Claudio Landolfi Pereira

E-mail: 1uizlandolfi@uol.com.br lucasabdopereira@uol.com.br 